Please do not remove this page

RMIT

UNIVERSITY

\title{
Do people with intersecting identities report more high-risk alcohol use and lifetime substance use?
}

Demant, Daniel; Oviedo-Trespalacios, Oscar; Carroll, Julie-Anne; Ferris, Jason; Maier, Larissa; Barratt, Monica; Winstock, Adam

https://researchrepository.rmit.edu.au/esploro/outputs/9921861180101341/filesAndLinks?institution=61RMIT_INST\&index=null

Demant, D., Oviedo-Trespalacios, O., Carroll, J.-A., Ferris, J., Maier, L., Barratt, M., \& Winstock, A. (2018). Do people with intersecting identities report more high-risk alcohol use and lifetime substance use? International Journal of Public Health, 63(5), 621-630. https://doi.org/10.1007/s00038-018-1095-5 Document Version: Accepted Manuscript

Published Version: https://doi.org/10.1007/s00038-018-1095-5

Repository homepage: https://researchrepository.rmit.edu.au

(C) Swiss School of Public Health (SSPH+) 2018

Downloaded On 2023/04/26 18:31:50 +1000 


\section{Do people with intersecting identities report more high risk alcohol use and}

\section{lifetime substance use?}

Daniel Demant, ${ }^{1,2}$ Oscar Oviedo-Trespalacios, ${ }^{3,4}$ Julie-Anne Carroll, ${ }^{2}$ Jason A. Ferris, ${ }^{5}$ Larissa Maier, ${ }^{6}$ Monica J. Barratt, ${ }^{7,8,9}$ Adam R. Winstock ${ }^{10,11}$

${ }^{1}$ Faculty of Health, University of Technology Sydney, Ultimo, Australia

${ }^{2}$ School of Public Health and Social Work \& Institute of Health and Biomedical Innovation (IHBI), Faculty of Health, Queensland University of Technology (QUT), Brisbane, Australia

${ }^{3}$ Centre for Accident Research and Road Safety - Queensland (CARRS-Q) \& Institute of Health and Biomedical Innovation (IHBI), Queensland University of Technology (QUT), Australia

${ }^{4}$ Universidad del Norte, Industrial Engineering Department, Engineering Faculty, Barranquilla Colombia

${ }^{5}$ Institute for Social Science Research, University of Queensland, Brisbane, Australia

${ }^{6}$ University of Zurich, Zurich, Switzerland

${ }^{7}$ Drug Policy Modelling Program, National Drug and Alcohol Research Centre, UNSW Australia, Sydney, Australia

${ }^{8}$ National Drug Research Institute, Faculty of Health Sciences, Curtin University, Perth, Australia

${ }^{9}$ Centre of Population Health, Burnet Institute, Melbourne, Australia

${ }^{10}$ University College London, London, UK

${ }^{11}$ Global Drug Survey Ltd, London, UK

\section{Corresponding Author:}

Daniel Demant

Faculty of Health, University of Technology Sydney, Ultimo, Australia

235 Jones Street, Ultimo, NSW, 2007, Australia

$\mathrm{T}:+61295145499$

E: daniel.demant@uts.edu.au 


\section{Introduction}

Intersectionality refers to the interconnected nature of social categorizations such as race/ethnicity, class or socio-economic status, sexual identity, and gender as they apply to a given individual or group, and draws attention to overlapping and interdependent systems of discrimination or disadvantage (Bowleg 2012; Rogers and Kelly 2011; O'Brien 2016). Thus, it is a conceptual tool for research and critical thought into how disadvantage is experienced within different social minority groups, and in particular, for considering and acknowledging those who fall into multiple groups (Molina et al 2016; Creswell 2014; Vardeman-Winter et al 2013; Bauer 2014). It is drawn from a sociopolitical theoretical framework aimed at understanding how people, who fall into multiple groups across categories experience increased social oppression (Rogers and Kelly 2011). Intersectionality often concentrates on social advantages and disadvantages associated with certain identities, and their consequences on social, emotional, physical, and mental wellbeing (Read and Eagle 2011). In this context, identities that experience societal oppression based on their identity are defined as 'disadvantaged identities' whereas identities not experiencing such oppression are defined as socially advantaged identities such as 'heterosexuals', 'men', or 'white people' (Watt 2007). Research into intersecting social identities is relatively new and currently not widely applied in public health research. In particular, little is known about intersectionality as a risk or a protective factor, nor about how specific intersecting identities affect health-related behaviours, morbidity, and mortality rates (Etherington 2015; Hankivsky et al. 2014). Advocates for the use of intersectionality as a research paradigm argue that without consideration of this framework in both theoretical and empirical studies, populations continue to be studied in ways that eliminate a consideration of the complex social realities of many sub-groups and individuals, and fail to take into account power inequity as it affects human health and wellbeing (Rogers and Kelly, 2011). Importantly, this theoretical lens allows us to examine variable relationships that we might expect to have compounding effects on disadvantage and health (Carliner et al. 2016; Clark et al. 2018).

Bowleg (2012) described intersectionality as crucial in light of public health's commitment to social justice, and states that health research cannot intelligently keep studies that take intersectionality into account a rarity. She argues that it should be an inherent part of health inequalities research due to its ability to 'reflect multiple interlocking systems of privilege and oppression at the macro and socialstructural levels, including racism, sexism, and heterosexism' (pg. 1267). Bauer (2014) agreed in so far as it should be used as a tool to generate evidence for the existence of intra-group and inter-group health inequalities that require a unique and contextually sensitive response in order to create and sustain social and public health progressions toward equity.

Beyond the use of this framework to drive the generation of epidemiological data as an evidence-base for social complexity and clusters in health inequalities, many researchers have recently gone on to advocate for the application of intersectionality when designing health promotion campaigns, 
social marketing, public health interventions, and the delivery of primary health care (Vardeman-Winter et al. 2013). Researchers in interdisciplinary fields, such as health-communication, found that campaigns and interventions require extensive research into the differing salient identities comprising target groups prior to efforts to instigate behavioural change, screening, and healthcare delivery (Nölke 2018; O’Brien 2016; Bauer 2014). As per any successful marketing or mass communication campaign, sub-groups who together compromise large sections of society - and who are often the target audiences for messages about lifestyle change and health - need to be comprehensively studied for insights into their unique living contexts. Viruell-Fuentes et al. (2012) made a progressive case for a shift away from assuming an understanding of the determinants of ill-health in these groups, and dedicated a specific research effort to going beyond cultural barriers to health in migrants. They suggested the varying structural inequalities experienced by different subsections of this group as more useful mechanisms and bases for designing interventions. This would help take into account unforeseen or seemingly 'invisible' structural barriers to health that more social advantaged or categorically less complex groups do not experience or express.

Some studies have found that if intersectionality is ignored in health service provision, the nature and quality of that service is compromised (Etherington 2017; Kelly and Rogers 2011). O'Brien et al. (2016) pointed to the need for considerations of gender and social class when providing services for services of domestic violence abuse (DVA), without which recipients of services feel misunderstood and undermined. Creswell (2014) noted that taking an intersectional approach to researching the needs of black women in the US generated outcomes that pointed to the need for taking stronger account of experiences of homelessness and overall mistrust of the system when delivering in-hospital care to these women. Hankivsky et al. (2014) advocated for an overall intersectionality-based policy analysis framework as a practical means to effectively redressing inequality, and for producing more inclusive and socially just platforms for service delivery. In particular, Hankivsky et al. (2014) argued that while we have looked at men's health, women's health, and gender and health per se, we need an integration of these research efforts to understand common struggles faced in each field, such as in the context of health services for those living with HIV/AIDS. One study, for example, revealed that highly educated black women still experienced poorer health than their equally educated white counterparts (Etherington 2015), suggesting that intersecting identities may be an important part of health research and practice.

However, the different ways in which intersectional identities play out in relation to health-risk behaviours and outcomes is not always clear. Intersectionality theory proposes that the effects of multiple minority or disadvantaged identities on health outcomes and behaviours are not merely additive in nature but complex and often counterintuitive (Bauer 2014). For example, contemporary literature on substance use and associated poor health identifies discrimination, oppression, as well as generally low wellbeing as factors affecting substance use behaviours (Priest et al. 2013; Frost and Meyer 2009). The majority of the body of literature associates substance use with low-income, 
marginalised, and disadvantaged groups (Blosnich et al. 2011; Pollock et al. 2012). The literature also shows that people with intersecting identities, that is combinations or overlap of these group identities, are more likely to be marginalised and discriminated against and show lower levels of mental wellbeing (Carliner et al. 2016; Molina et al. 2016; Cook et al. 2016). Carliner et al. (2016) found that while racial discrimination against black Americans contributed to higher rates of illicit drug use, this relationship was even stronger amongst higher socioeconomic sections of this ethnic group. Further, Molina et al. (2016) found that while racial discrimination against Latinos generated higher risks of problematic alcohol use and smoking across men and women, men who identified strongly with their ethic/racial group were significantly more likely to be a current smoker than any other group. An interesting study by Cook et al. (2016) found that young men in the US aged 18 were more likely than the authors hypothesised to be forced into sex by woman (6\% of men). Also, victims of assault by women were more likely to be engaging in substance use, specifically cannabis and crack cocaine. These kinds of findings highlight traditionally protective factors as ones that compound disadvantage in some circumstances. While the current body of literature provides some insight into the ways in which intersectionality affects health-risk behaviours in unexpected and complex ways (Walby et al 2012; Constance-Huggins 2018; Esposito and Edwards 2018), research on intersecting identities and substance use as well as intersectional health research beyond single-country samples is scarce. Furthermore, studies often concentrate on intersections with two identities, losing sight of highly complex and over-lapping social identities, and the ways in which these many lesser explored combinations impact differently on substance use behaviours.

This paper presents the results of an intersectional analysis of a large international sample, addressing issues of substance use behaviour and risk among people with disadvantaged social identities, and the influence of potential interactions among those with multiple disadvantaged social identities. The aim of this paper is to identify protective and non-protective identity intersections and to determine the strength of relationships between social identities and intersections, and lifetime substance use as well as high risk and harmful alcohol use.

\section{Methods}

\section{Survey design}

The Global Drug Survey (GDS) is the world's largest annually conducted substance use survey. The GDS uses a non-probability sampling strategy with a self-administered anonymous online survey, available in ten different languages (Barratt et al. 2017). Social media platforms and media partners in 19 countries were used to recruit participants for GDS2015. Questions are developed and reviewed by an expert advisory committee comprised of individuals with extensive expertise in the substance use area such as substance use researchers, psychologists, substance user representatives, and legal experts. 
Data from the 2015 wave of GDS (collected between November 11, 2014 and January 03, 2015) was and Maudsley National Health Service, the Institute of Psychiatry Joint Research Ethics Committee, and University of Queensland (Reference: 2017001452/11671/001). All participants provided informed consent before commencing the survey.

\section{Variables and measures}

Substances. This analysis includes binary variables on lifetime (yes/no) use of nine different substances: alcohol (also past year use), tobacco, cannabis, cocaine, amphetamine, MDMA (ecstasy), ketamine, methamphetamine, and GHB (gamma hydroxybutyrate). Commonly injected substances such as heroin were excluded from the analysis due to very low rates of lifetime use within the sample; however, all illicit substances in the data set were combined into one separate binary variable.

Alcohol Use. The Alcohol Use Disorders Identification Test (AUDIT) was used to analyse drinking behaviour. AUDIT uses 10 standardised questions to calculate a score (range: 0 to 40), and has shown to be a valid and reliable measurement to identify patients with high risk/harmful levels of alcohol use at a cut-off of 15 points (Babor et al. 2001). Since alcohol is the most commonly used substance world-wide, lifetime use rates of alcohol are often not useful in largely adult samples as disparities will be at extremely low levels (Degenhardt et al. 2015; Daeppen et al. 2000).

Demographic variables. Demographic indicators used for this analysis are age, educational level, country of residence, employment status, ethnicity, sexual identity, and gender.

\section{Analysis}

A total of 101,311 survey responses were submitted. After preparing the data, 3,456 records were excluded due to data capture glitches, duplicate entries, missing data on key variables (age, sex and drug screen items), and the reporting of using a fake drug. A further 6,914 participants were excluded from the analysis due to missing data on variables included in the analysis, with 4,200 excluded for missing data on sexual orientation including 2,208 participants who preferred not to disclose their sexual orientation. Ethnicity and sexual orientation variables were recoded into dichotomous variables differentiating between majority/social advantaged social identity groups and minority identity status/disadvantaged social identities: Ethnicity (White/Caucasian as the socially advantaged identity and all other as the disadvantaged social identity), sexual orientation (heterosexuals as the social advantaged social identity and all other as the disadvantaged social identity). An international sample was used for this analysis including countries with various cultural backgrounds and traditions regarding the treatment of minorities. However, evidence suggests that all groups of interest for this research - females, non-White ethnicities, and sexual minorities - are socially 
disadvantaged across nations (Weiss and Bosia 2013; Chow et al. 2011) including nations in which, for example, non-White ethnicities are in the majority (Bhattacharyya et al. 2016).

Descriptive analyses were conducted for sample characteristics (see Table 1). Multivariable logistic regressions were conducted to calculate adjusted odds ratios (AORs) of lifetime substance use (see Table 2) as well as harmful/high risk alcohol use (see Table 3). Disadvantaged social identity variables (ethnicity, sexual orientation, and gender), and demographic variables that have been found to influence substance use such as age, education, country of residence, and employment status (United Nations Office on Drugs and Crime 2015) were entered as independent variables using the majority/socially advantaged social identity as the reference category. Country of residence was entered as a fixed factor to account for potential differences between countries regarding legal systems and general substance use culture. Intersecting identities were entered as two-way and three-way interactions. Confidence intervals and probability values were calculated, but should be interpreted with caution due to the non-probabilistic nature of the sample. IBM SPSS Statistics Version 22 was used for all analyses.

\section{Results}

Sample characteristics

The final sample used for analysis consisted of 90,941 participants with a mean age of 29.3 years (see Table 1). Most participants identified as male $(62.1 \%, n=56,469)$, white/Caucasian $(91.7 \%, n=83,390)$, and heterosexual $(86.5 \%, \mathrm{n}=78,631)$. Overall, participants possessed high levels of education with $30.1 \%(\mathrm{n}=27,231)$ and $14.2 \%(\mathrm{n}=12,860)$ having undergraduate and postgraduate university degrees, respectively. One third $(33 \%, \mathrm{n}=29,969)$ of participants resided in Germany, and the 10 most common countries accounted for $84.2 \%$ of all participants.

\section{Substance use among individual minority groups}

Ethnicity. A total of 7,551 (8.3\%) participants identified with a disadvantaged ethnic identity (see Table 1). Participants with a disadvantaged ethnic identity showed significantly higher AORs for lifetime substance (see Table 2 and 3) use for all substances included in this analysis except for tobacco and amphetamine, ranging from 1.24 (95-\%-CI: 1.11-1.39, p<0.001) for ketamine to 2.45 (95-\%-CI: 2.00-3.01, $\mathrm{p}<0.001)$ for lifetime alcohol use. However, these participants showed a significantly lower AOR for past year alcohol use (AOR=0.76; 95-\%-CI: 0.66-0.87, $\mathrm{p}<0.001)$; no differences in high risk/harmful alcohol use were detected.

Sexual minority identities. A total of $12,310(13.5 \%)$ participants identified with a sexual minority identity (see Table 1). Sexual minority participants showed higher AORs for lifetime use of 
all illicit substances, amphetamine, cocaine, MDMA, ketamine, methamphetamine, and GHB, ranging from 1.20 (95-\%-CI: 1.13-1.27, p<0.001) for amphetamine to 3.48 (95-\%-CI: 3.17-3.83, p<0.001) for GHB. No differences in the use of tobacco, cannabis, and alcohol were found; however, sexual minority participants showed a significantly higher AOR for high risk/harmful alcohol use (AOR: 1.15, 95-\%CI: $1.06-1.24, \mathrm{p}<0.01)$.

Female participants. Female comprised 37.9\% $(n=34,472)$ of the sample (see Table 1). Rates of substance use is generally lower among females compared to their male counterparts. AORs are significantly lower for all substances except lifetime alcohol use (AOR: 1.13, 95-\%-CI: 1.00-1.26 $\mathrm{p}<0.05$ ), ranging from 0.48 (95-\%-CI: 0.48-0.52, $\mathrm{p}<0.001$ ) for all illicit substances and cannabis to 0.73 (95-\%-CI: 0.66-0.80, p<0.001) for GHB.

\section{Substance use and intersecting identities}

Intersection 1: ethnicity and sexual orientation. No significant differences could be detected for 8 substances (amphetamine, tobacco, cocaine, MDMA, ketamine, methamphetamine, GHB, lifetime alcohol use, and past-year alcohol use) as well as for all illicit substances combined. Participants with an identity in this intersection have a significantly lower AORs for the use of all illicit substances (AOR: 0.71, 95-\%-CI: 0.55-0.93, p<0.05), cannabis (AOR: 0.72, 95-\%-CI: 0.57-0.90, p<0.01), and high risk/harmful alcohol use (AOR: 0.70, 95-\%-CI: 0.53-0.94, $\mathrm{p}<0.05$ ).

Intersection 2: ethnicity and gender. AORs were significantly lower for six substances: all illicit substances (AOR: 0.59, 95-\%-CI: 0.51-0.68,p<0.001), tobacco (AOR: 0.80, 95-\%-CI: 0.700.91,p<0.01), cannabis (AOR: 0.61, 95-\%-CI: 0.53-0.70, p<0.001), cocaine (AOR: 0.78, 95-\%-CI: 0.69-0.87, p<0.001), MDMA (AOR: 0.81, 95-\%-CI: 0.72-0.91, p<0.001), and methamphetamine (AOR: 0.61, 95-\%-CI: 0.45-0.84, p<0.01); no significant differences were detected for amphetamine, ketamine, and GHB as well as lifetime/past year and high risk/harmful alcohol use. Participants with this intersecting identity had higher AORs for all substances except methamphetamine and past year alcohol consumption than females alone and lower AORs for all substances than ethnic minority participants except past year alcohol consumption. However, participants with this intersecting identity showed lower AORs for high risk/harmful alcohol consumption (AOR: 0.70, 95-\%-CI: 0.53-0.94, $\mathrm{p}<0.05)$ than both female and ethnic minority participants alone.

Intersection 3: gender and sexual orientation. AORs for substance use were significantly higher for six substances: all illicit substances combined (AOR: 1.47, 95-\%-CI: 1.30-1.66, p<0.001), amphetamine (AOR: 1.62, 95-\%-CI: 1.47-1.78, p<0.001), tobacco (AOR: 1.76, 95-\%-CI: 1.56-1.98, $\mathrm{p}<0.001$ ), cannabis (AOR: 2.02, 95-\%-CI: 1.81-2.25, p<0.001), cocaine (AOR: 1.23, 95-\%-CI: 1.131.35, $\mathrm{p}<0.001$ ), and MDMA (AOR: 1.26, 95-\%-CI: 1.15-1.37, $\mathrm{p}<0.001$ ). AORs for GHB use were significantly lower (AOR: $0.58,95-\%$-CI: $0.49-0.69, \mathrm{p}<0.001$ ) and no significant differences could be detected for ketamine and methamphetamine as well as lifetime and past year alcohol use. However, 
participants with this intersecting identity had a higher AOR of high risk/harmful alcohol use (AOR: 1.37, 95-\%-CI: 1.21-1.55, $\mathrm{p}<0.001)$. Participants with this intersection had higher AORs for all substances compared to females alone with the exception of lifetime and past year alcohol use. They also showed higher AORs than those with a sexual minority identity alone for all illicit substances, amphetamine, tobacco, cannabis, cocaine, MDMA, and lower AORs for ketamine, methamphetamine, GHB as well as lifetime, past year and high risk/harmful alcohol consumption.

Intersection 4: Ethnic minority, sexual minority, and female. Participants with this intersecting identity have significantly higher AORs of substance use for four substances: all illicit substances (AOR: 2.08, 95-\%-CI: 1.44-3.02, p<0.001), cannabis (AOR: 2.1, 95-\%-CI: 1.49-2.94, p<0.001), cocaine (AOR: 1.36, 95-\%-CI: 1.05-1.77, p<0.05), and MDMA (AOR: 1.41, 95-\%-CI: 1.09-1.83, $\mathrm{p}<0.05)$. No significant differences could be detected for other substances or high risk/harmful alcohol use. Compared with participants in intersection 1 (ethnicity and sexual orientation), participants in this intersection showed higher AORs for all substances except ketamine, GHB, and past year alcohol use. Similarly they also showed higher AORs for all substances except tobacco, ketamine and high risk/harmful alcohol consumption compared to those in intersection 3 (sex and sexual orientation) as well as higher AORs than those in intersection 2 (ethnicity and sex) for all substances except past year and high risk/harmful alcohol consumption.

\section{Discussion}

This paper addresses issues of substance use among people with disadvantaged social identities and the potential influence of interactions between these identities on substance use disparities. The current body of literature on substance use identifies discrimination, oppression, and marginalisation (Gibbons et al. 2012; Meyer 2003) as well as generally low wellbeing (Degenhardt et al. 2001; Merline et al. 2004) as factors increasing substance use behaviours. Literature also shows that people with intersecting identities are more likely to be marginalised and discriminated against and have lower levels of wellbeing (Frost and Meyer 2009; Meyer 2003; Priest et al. 2013; Stuber et al. 2008).

The analysis of this study suggests that participants with disadvantaged ethnic identities or a sexual minority identity are meaningfully more likely to be involved in substance use in their lifetime. The third group of participants with a disadvantaged social identity in this analysis, females, are generally less likely to experience substance use and high risk/harmful alcohol use than their male counterparts. This analysis also shows that participants with multiple intersecting identities are not necessarily more likely to experience substance use than those without or only one minority or oppressed identity. Results suggest that participants with an intersecting identity comprised of a disadvantaged ethnic identity and a sexual minority identity are considerably less likely to use substances and consume alcohol in a high risk or harmful way than those without this intersecting 
identity. Participants with this intersection identity also showed generally lower AORs than those the context of substance use. This effect could not be observed for the intersection of ethnic minorities and female identities, showing that ethnic minority females are less likely to use substances than ethnic minority participants in general but more than females in general.

Similarly, the analysis of the intersecting identity of females and sexual minority shows an increase in lifetime substance use behaviour as well riskier alcohol use. Finally, this analysis showed that a more complex intersecting identity between ethnic and sexual minority and females may not be protective for all groups. Participants with these intersecting identities are generally more likely to experience substance than all other intersecting identities in this analysis.

Previous studies showed lower levels of substance use for females and heterosexuals compared to males and sexual minority participants, respectively, consistent with the results of this analysis (Agaku et al. 2014; Hatzenbuehler et al. 2014). Current literature also supports the conclusion that females with intersecting identities may be at higher risk of substance use (Marshal et al. 2008; Mereish and Bradford 2014) whilst sexual and ethnic minority are at a lower risk of substance use than their respective white counterparts (Blosnich et al. 2011; Mereish and Bradford 2014; Pollock et al. 2012). This analysis showed that these trends are consistent using a variety of substances in an international sample beyond English-speaking countries.

\section{Strengths and limitations}

The study has some limitations. Participants responding to the Global Drug Survey were more likely to be younger, higher educated, and sexually diverse than the general population, while women and ethnic minorities were underrepresented. There are multiple potential reasons for these differences including the recruitment through media partners often described as politically liberal as well as the name of the study potentially attracting populations known for higher rates of substance use such as men (compared to women). This may inflate rates of substance use observed in this study. Similarly, participants are self-enrolled, further restricting the generalisability of results. However, the design of this survey might be better than population surveys at recruiting participants from hard-to-reach populations such as people with an intersecting identity (Barratt et al. 2017). A small number of participants with complex intersecting identities may not be included in the analysis due to missing data on sexual orientation. It is not clear why a considerable number of participants prefers not to disclose their sexual orientation. Participants may be uncertain about their own sexual orientation or feel uncomfortable to disclose their sexual orientation due to various reasons such as living in an environment perceived to be hostile towards sexual minority identities. Furthermore, it is unknown how many participants used a substance only once; lifetime substance use might therefore not be the most reliable measurement. However, this limitation does not explain the differences found in this analysis. 
Previous research has also identified marital status as a protective factor against substance use (Merline

\section{Conclusion}

Overall, among people responding to a web survey on substance use, people who belong to an ethnic and/or sexual minority were more likely to report the use of various substances across their lifetime. The findings support the need of more research into the health of people with intersecting identities as a public health priority, particular in regards to disparities in substance use outcomes in sexual minority women from an ethnic minority. Similarly, qualitative studies are needed to identify potential coping strategies used by sexual minority men from an ethnic minority, why these are not employed by or do not work for sexual minority women. Furthermore, research into the effects and potential role of minority communities on substance use are needed, especially on how positive mechanisms in these communities can be used in designing public health interventions. Future study designs should ensure that people with a minority identity are sufficiently reached, for example by partnering with community media and within social media networks.

\section{Ethical statement}

All procedures performed in studies involving human participants were in accordance with the ethical standards of the institutional and/or national research committee and with the 1964 Helsinki declaration and its later amendments or comparable ethical standards.

\section{Acknowledgements}

Global Drug Survey is a self-funded organisation; its media partners did not have any role in the design, interpretation or write-up of this paper. ARW is the founder and managing director of Global Drug Survey. All authors have contributed to the design, interpretation and write-up of the manuscript. We would like to thank the participants who gave so generously of their time to complete the GDS. We are grateful for the promotion of GDS by a long list of world media partners, see Barratt et al. (2007). We are also indebted to Stuart Newman for his programming skills, advice and patience and Chris Parsons for his hard work in managing the translation site for the survey.

\section{Funding sources}

The authors received no specific financial support for the research, authorship, and/or publication of this study. MJB and JAF were supported by fellowships from the Australian National Health and Medical Research Council (APP1070140, APP1089395). The National Drug and Alcohol Research Centre and the National Drug Research Institute were supported by funding from the 
Australian Government under the Substance Misuse Prevention and Service Improvement Grants Fund. We also acknowledge the contribution of the Victorian Operational Infrastructure Support Program received by the Burnet Institute. 


\section{References}

Agaku IT, King BA et al. (2014) Tobacco product use among adults — United States, 2012-2013. Morbidity and Mortality Weekly Report 63:542-547

Babor T, Higgins-Biddle J, Saunders J, Monteiro M (2001) AUDIT - The alcohol use disorders identification test (guidelines for use in primara care). Geneva, Switzerland

Barratt MJ, Ferris J et al. (2017) Moving on from representativeness: testing the utility of the Global Drug Survey. Subst Abuse 11:1-17. https://doi.org/10.1177/1178221817716391

Bauer GR (2014) Incorporating intersectionality theory into population health research methodology: challenges and the potential to advance health equity. Soc Sci Med 110:10-17. https://doi.org/10.1016/j.socscimed.2014.03.0221

Blosnich J, Jarrett T, Horn K (2011) Racial and ethnic differences in current use of cigarettes, cigars, and hookahs among lesbian, gay, and bisexual young adults. Nicotine Tob Res 13:487-491. https://doi.org/10.1093/ntr/ntq261

Bowleg L (2012) The problem with the phrase women and minorities: intersectionality-an important theoretical framework for public health. Am J Public Health 102:1267-1273. https://doi.org/10.2105/ajph.2012.300750

Carliner H, Delker E, Fink DS, Keyes KM, Hasin DS (2016) Racial discrimination, socioeconomic position, and illicit drug use among US Blacks. Soc Psychiatry Psychiatric Epidemiol 51:551560. https://doi.org/10.1007/s00127-016-1174-y

Chow EN-L, Segal MT, Lin T, Demos VP, Segal MT (2011) Analyzing Gender, Intersectionality, and Multiple Inequalities: Global-transnational and Local Contexts. Emerald Group Publishing Limited, Bingley

Clark C, Matthew D, Burns V (2018) Power, privilege and justice: intersectionality as human rights? Int J Hum Rights 22:108-126. https://doi.org/10.1080/13642987.2017.1390333

Constance-Huggins M (2018) Intersection of race, gender, and nationality in teaching about race and racism. Reflective Practice 19:81-88. https://doi.org/10.1080/14623943.2017.1361918

Cook MC, Morisky DE, Williams JK, Ford CL, Gee GC (2016) Sexual Risk Behaviors and Substance Use Among Men Sexually Victimized by Women. Am J Public Health 106:1263-1269. https://doi.org/10.2105/ajph.2016.303136

Creswell LM (2014) A critical black feminist ethnography of treatment for women with co-occurring disorders in the psychiatric hospital. J Behav Health Serv Res 41:167-184. https://doi.org/10.1007/s11414-013-9344-0

Daeppen JB, Yersin B, Landry U, Pecoud A, Decrey H (2000) Reliability and validity of the Alcohol Use Disorders Identification Test (AUDIT) imbedded within a general health risk screening questionnaire: results of a survey in 332 primary care patients. Alc Clin Exp Res 24:659-665. https://doi.org/10.1111/j.1530-0277.2000.tb02037.x 
Degenhardt L, Hall, Wayne (2001) The relationship between tobacco use, substance-use disorders and mental health: results from the National Survey of Mental Health and Well-being. Nicotine Tob Res 3:225-234. https://doi.org/10.1080/14622200110050457

Degenhardt L, Hall W, Gartner C (2015) The epidemiology of tobacco, alcohol, and illicit drug use and their contribution to the burden of disease. In: Haber P, Day C, Farrell M (ed) Addiction Medicine: Principles and Practice. IP Communications, Melbourne, pp 8-21

Esposito J, Edwards EB (2017) When Black Girls Fight: Interrogating, Interrupting, and (Re)Imagining Dangerous Scripts of Femininity in Urban Classrooms. Educ Urban Soc 50:87-107. https://doi.org/10.1177/0013124517729206

Etherington N (2015) Race, Gender, and the Resources That Matter: An Investigation of Intersectionality and Health. Women Health 55:754-777. https://doi.org/10.1080/03630242.2015.1050544

Frost DM, Meyer IH (2009) Internalized homophobia and relationship quality among lesbians, gay men, and bisexuals. J Couns Psychol 56:97-109. https://doi.org/10.1037/a0012844

Gibbons FX, O'Hara RE, Stock ML, Gerrard M, Weng C-Y, Wills TA (2012) The erosive effects of racism: Reduced self-control mediates the relation between perceived racial discrimination and substance use in African American adolescents. Journal Pers Soc Psychol 102:1089-1104. https://doi.org/10.1037/a0027404

Hankivsky O (2012) Women's health, men's health, and gender and health: implications of intersectionality. Soc Sci Med 74:1712-1720. https://doi.org/10.1016/j.socscimed.2011.11.029

Hankivsky O et al. (2014) An intersectionality-based policy analysis framework: critical reflections on a methodology for advancing equity. Int $\mathbf{J}$ Equity Health 13:119. https://doi.org/10.1186/s12939-014-0119-x

Hatzenbuehler ML, Keyes KM, Hamilton A, Hasin DS (2014) State-level tobacco environments and sexual orientation disparities in tobacco use and dependence in the USA. Tob Control 23:e127132. https://doi.org/10.1136/tobaccocontrol-2013-051279

Marshal MP et al. (2008) Sexual orientation and adolescent substance use: a meta-analysis and methodological review. Addiction 103:546-556. https://doi.org/10.1111/j.13600443.2008.02149.x

Mereish EH, Bradford JB (2014) Intersecting identities and substance use problems: sexual orientation, gender, race, and lifetime substance use problems. J Stud Alcohol Drugs 75:179-188. https://doi.org/10.15288/jsad.2014.75.179

Merline AC, O’Malley PM, Schulenberg JE, Bachman JG, Johnston LD (2004) Substance Use Among Adults 35 Years of Age: Prevalence, Adulthood Predictors, and Impact of Adolescent Substance Use. Am J Public Health 94:96-102. https://doi.org/10.2105/AJPH.94.1.96 
Meyer IH (2003) Prejudice, social stress, and mental health in lesbian, gay, and bisexual populations:

Conceptual issues and research evidence. Psychol Bull 129:674-697. https://doi.org/10.1037/0033-2909.129.5.674

Molina KM, Jackson B, Rivera-Olmedo N (2016) Discrimination, Racial/Ethnic Identity, and Substance Use Among Latina/os: Are They Gendered? Ann Beh Med 50:119-129. https://doi.org/10.1007/s12160-015-9738-8

Nölke A-I (2018) Making Diversity Conform? An Intersectional, Longitudinal Analysis of LGBTSpecific Mainstream Media Advertisements. J Homosexuality 65:224-255. https://doi.org/10.1080/00918369.2017.1314163

O’Brien RB (2016) Intersectionality and adolescent domestic violence and abuse: addressing "classed sexism" and improving service provision. Int J Human Rights Healthc 9:161-173. https://doi.org/10.1108/IJHRH-08-2015-0026

Pollock JA et al. (2012) Alcohol use among young men who have sex with men. Subst Use Misuse 47:12-21. https://doi.org/10.3109/10826084.2011.618963

Priest N, Paradies Y, Trenerry B, Truong M, Karlsen S, Kelly Y (2013) A systematic review of studies examining the relationship between reported racism and health and wellbeing for children and young people. Soc Sci Med 95:115-127. https://doi.org/10.1016/j.socscimed.2012.11.031

Read JG, Eagle DE (2011) Intersecting identities as a source of religious incongruence. J Sci Study Religion 50:116-132. https://doi.org/10.1111/j.1468.5906.2010.01555.x

Rogers J, Kelly UA (2011) Feminist intersectionality: bringing social justice to health disparities research. Nursing ethics 18:397-407. https://doi.org/10.1177/0969733011398094

Stuber J, Meyer I, Link B (2008) Stigma, prejudice, discrimination and health. Soc Sci Med 67:351357. https://doi.org/10.1016/j.socscimed.2008.03.023

United Nations Office on Drugs and Crime (2015) World Drug Report 2015. New York

Vardeman-Winter J, Jiang H, Tindall NTJ (2013) Information-Seeking Outcomes of Representational, Structural, and Political Intersectionality Among Health Media. J Appl Commun Res 41:389411. https://doi.org/10.1080/00909882.2013.828360

Viruell-Fuentes EA, Miranda PY, Abdulrahim S (2012) More than culture: structural racism, intersectionality theory, and immigrant health. Soc Sci Med 75:2099-2106. https://doi.org/10.1016/j.socscimed.2011.12.037

Walby S, Armstrong J, Strid S (2012) Intersectionality: Multiple Inequalities in Social Theory. Soc 46:224-240. https://doi.org/10.1177/0038038511416164

Watt SK (2007) Difficult dialogues, privilege and social justice: Uses of the privileged identity exploration (PIE) model in student affairs practice. College Student Affairs Journal 26:114.

Weiss ML, Bosia MJ (2013) Global homophobia: States, movements, and the politics of oppression. University of Illinois Press, Illinois. 
Table 1: Global Drug Survey (2015) sample characteristics $(\mathrm{n}=90,941)$

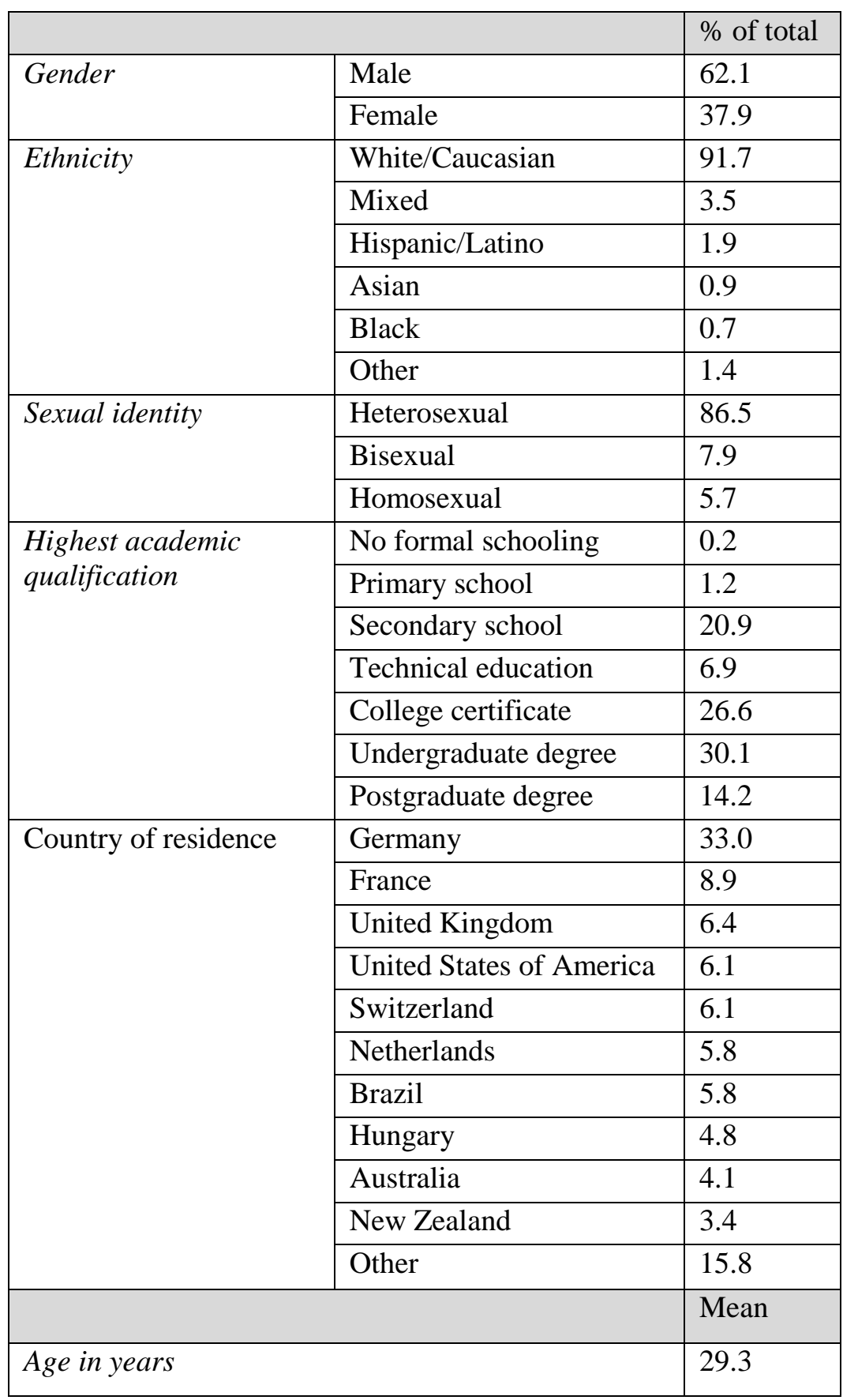


Table 2: Adjusted Odds Ratios of Lifetime Substance Use by Identity, Global Drug Survey (2015)

\begin{tabular}{|c|c|c|c|c|c|c|c|c|c|c|c|c|c|c|c|c|c|c|}
\hline \multirow{2}{*}{ Variables } & \multicolumn{2}{|c|}{ All illicit substances } & \multicolumn{2}{|c|}{ Amphetamine } & \multicolumn{2}{|c|}{ Tobacco } & \multicolumn{2}{|c|}{ Cannabis } & \multicolumn{2}{|c|}{ Cocaine } & \multicolumn{2}{|c|}{ MDMA $^{\varepsilon}$} & \multicolumn{2}{|c|}{ Ketamine } & \multicolumn{2}{|c|}{ Methamphetamine } & \multicolumn{2}{|c|}{ GHB $^{\#}$} \\
\hline & $\mathbf{A O R}^{\wedge}$ & $95 \% \mathrm{CI}$ & $\mathbf{A O R}^{\wedge}$ & $95 \%$ CI & $\mathrm{AOR}^{\wedge}$ & $95 \% \mathrm{CI}$ & $\mathbf{A O R}^{\wedge}$ & $95 \%$ CI & $\mathbf{A O R}^{\wedge}$ & $95 \% \mathrm{CI}$ & $\mathbf{A O R}^{\wedge}$ & $95 \% \mathrm{CI}$ & $\mathbf{A O R}^{\wedge}$ & $95 \% \mathrm{CI}$ & $\mathbf{A O R}^{\wedge}$ & $95 \% \mathrm{CI}$ & $\mathbf{A O R}^{\wedge}$ & $95 \% \mathrm{CI}$ \\
\hline \multicolumn{19}{|l|}{ Ethnicity } \\
\hline White/Caucasian & $1 \dagger$ & & $1 \dagger$ & & $1 \dagger$ & & $1 \dagger$ & & $1 \dagger$ & & $1 \dagger$ & & $1 \dagger$ & & $1 \dagger$ & & $1 \dagger$ & \\
\hline Ethnic Minority & $1.51 * * *$ & $1.35-1.68$ & 0.94 & $0.86-1.02$ & 0.93 & $0.84-1.02$ & $1.46^{* * * *}$ & $1.32-1.62$ & $1.51 * * *$ & $1.40-1.62$ & $1.40 * * *$ & $1.30-1.51$ & $1.24 * * *$ & $1.11-1.39$ & 1.69 *** & $1.45-1.97$ & 1.46 **** & $1.22-1.76$ \\
\hline \multicolumn{19}{|l|}{ Sexual Orientation } \\
\hline Heterosexual & $1 \dagger$ & & $1 \dagger$ & & $1 \dagger$ & & $1 \dagger$ & & $1 \dagger$ & & $1 \uparrow$ & & $1 \dagger$ & & $1 \dagger$ & & $1 \dagger$ & \\
\hline Sexual Minority & $1.42 * * *$ & $1.31-1.54$ & 1.20 *** & $1.13-1.27$ & $0.92 *$ & $0.86-0.99$ & 0.97 & $0.91-1.05$ & $1.44 * * *$ & $1.37-1.52$ & $1.47 * * *$ & $1.39-1.55$ & $1.88 * * *$ & $1.75-2.01$ & 2.30 **** & $2.09-2.54$ & 3.48 **** & $3.17-3.83$ \\
\hline \multicolumn{19}{|l|}{ Sex } \\
\hline Male & $1 \dagger$ & & $1 \dagger$ & & $1 \dagger$ & & $1 \dagger$ & & $1 \dagger$ & & $1 \dagger$ & & $1 \dagger$ & & $1 \dagger$ & & $1 \dagger$ & \\
\hline Female & $0.50 * * *$ & $0.48-0.52$ & $0.55^{* * * *}$ & $0.53-0.57$ & $0.66^{* * * *}$ & $0.63-0.68$ & $0.50^{\text {**** }}$ & $0.48-0.52$ & $0.63 * * *$ & $0.61-0.65$ & $0.62 * * *$ & $0.60-0.64$ & $0.55^{* * * *}$ & $0.52-0.58$ & $0.65 * * *$ & $0.59-0.71$ & $0.73 * * *$ & $0.66-0.80$ \\
\hline \multicolumn{19}{|l|}{ Intersections } \\
\hline $\begin{array}{l}\text { Ethnicity } \times \text { Sexual } \\
\text { orientation }\end{array}$ & $0.71^{*}$ & $0.55-0.93$ & 0.97 & $0.78-1.21$ & 1.07 & $0.85-1.35$ & $0.72 * *$ & $0.57-0.90$ & 0.85 & $0.71-1.02$ & 0.88 & $0.73-1.05$ & 1.16 & $0.92-1.46$ & 0.91 & $0.67-1.24$ & 1.10 & $0.81-1.49$ \\
\hline Ethnicity $\times$ Sex & $0.59 * * *$ & $0.51-0.68$ & 0.98 & $0.84-1.15$ & $0.80 * *$ & $0.70-0.91$ & $0.61 * * *$ & $0.53-0.70$ & $0.78 * * *$ & $0.69-0.87$ & $0.81 * * *$ & $0.72-0.91$ & 0.99 & $0.82-1.20$ & $0.61 * *$ & $0.45-0.84$ & 0.88 & $0.64-1.20$ \\
\hline $\begin{array}{l}\text { Sex } \times \text { Sexual } \\
\text { orientation }\end{array}$ & $1.47^{* * *}$ & $1.30-1.66$ & $1.62^{* * * *}$ & $1.47-1.78$ & $1.76^{* * * *}$ & $1.56-1.98$ & $2.02 * * *$ & $1.81-2.25$ & $1.23 * * *$ & $1.13-1.35$ & $1.26^{* * * *}$ & $1.15-1.37$ & 1.08 & $0.96-1.22$ & 0.98 & $0.82-1.17$ & $0.57 * * *$ & $0.47-0.69$ \\
\hline $\begin{array}{l}\text { Ethnicity } \times \operatorname{Sex} \times \\
\text { Sexual orientation }\end{array}$ & $2.08 * * *$ & $1.44-3.02$ & 1.04 & $0.75-1.45$ & 1.38 & $0.98-1.95$ & $2.10^{* * * *}$ & $1.49-2.94$ & $1.36^{*}$ & $1.05-1.77$ & $1.41^{*}$ & $1.09-1.83$ & 1.05 & $0.74-1.50$ & 1.32 & $0.77-2.27$ & 0.99 & $0.58-1.70$ \\
\hline
\end{tabular}

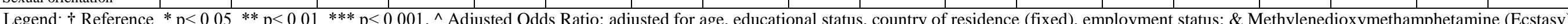

\# Gamma-hydroxybutyrate 
Table 3: Lifetime, Recent, and High Risk/Harmful Alcohol Consumption by Identity, Global Drug Survey (2015)

\begin{tabular}{|c|c|c|c|c|c|c|}
\hline \multirow[t]{2}{*}{ Variables } & \multicolumn{2}{|c|}{ Alcohol (Lifetime) } & \multicolumn{2}{|c|}{ Alcohol (Last year) } & \multicolumn{2}{|c|}{$\begin{array}{l}\text { High Risk/Harmful } \\
\text { Alcohol Consumption }\end{array}$} \\
\hline & $\mathbf{A O R}^{\wedge}$ & $95 \% \mathrm{CI}$ & $\mathbf{A O R}^{\wedge}$ & $95 \% \mathrm{CI}$ & AOR $^{\wedge}$ & $95 \% \mathrm{CI}$ \\
\hline \multicolumn{7}{|l|}{ Ethnicity } \\
\hline White/Caucasian & $1 \uparrow$ & & $1 \dagger$ & & $1 \dagger$ & \\
\hline Ethnic Minority & $2.45^{* * *}$ & $2.00-3.01$ & $0.76^{* * *}$ & $0.66-0.87$ & 1.02 & $0.91-1.13$ \\
\hline \multicolumn{7}{|l|}{$\begin{array}{l}\text { Sexual } \\
\text { Orientation }\end{array}$} \\
\hline Heterosexual & $1 \dagger$ & & $1 \dagger$ & & $1 \uparrow$ & \\
\hline Sexual Minority & 1.08 & $0.85-1.36$ & 1 & $0.89-1.12$ & $1.15 * *$ & $1.06-1.24$ \\
\hline \multicolumn{7}{|l|}{ Sex } \\
\hline Male & $1 \dagger$ & & $1 \uparrow$ & & $1 \uparrow$ & \\
\hline Female & $1.20 * *$ & $1.05-1.38$ & $0.92 *$ & $0.86-0.99$ & $0.63 * * *$ & $0.59-0.66$ \\
\hline \multicolumn{7}{|l|}{ Intersections } \\
\hline $\begin{array}{l}\text { Ethnicity } \times \text { Sexual } \\
\text { orientation }\end{array}$ & 0.58 & $0.32-1.03$ & 1.28 & $0.88-1.84$ & $0.70 *$ & $0.53-0.94$ \\
\hline Ethnicity $\times$ Sex & 0.78 & $0.58-1.07$ & 0.96 & $0.78-1.19$ & 1.09 & $0.91-1.3$ \\
\hline $\begin{array}{l}\text { Sex } \times \text { Sexual } \\
\text { orientation }\end{array}$ & 0.85 & $0.59-1.23$ & 0.83 & $0.69-1.00$ & $1.36 * * *$ & $1.19-1.54$ \\
\hline $\begin{array}{l}\text { Ethnicity } \times \operatorname{Sex} \times \\
\text { Sexual orientation }\end{array}$ & 0.98 & $0.41-2.35$ & 0.95 & $0.57-1.58$ & 1.06 & $(0.70-1.59$ \\
\hline
\end{tabular}

Legend: $\uparrow$ Reference, ${ }^{*} \mathrm{p}<0.05,{ }^{* *} \mathrm{p}<0.01,{ }^{* * *} \mathrm{p}<0.001,{ }^{\wedge}$ Adjusted Odds Ratio, adjusted for age, educational status, country of residence, employment status, \# Alcohol Use Disorders Identification Test (AUDIT) score above 15 